\title{
Evaluation of safety and tolerability of antiretroviral therapy in pregnant and non-pregnant women
}

\author{
Kamini Tyagi*, Veena Gupta
}

Department of Obstetrics \& Gynaecology, M.L.N. Medical College, Allahabad, Uttar Pradesh, India

\author{
Received: 31 March 2015 \\ Revised: 08 May 2015 \\ Accepted: 09 May 2015

\section{*Correspondence:} \\ Dr. Kamini Tyagi, \\ E-mail: td.kamini@gmail.com
}

Copyright: () the author(s), publisher and licensee Medip Academy. This is an open-access article distributed under the terms of the Creative Commons Attribution Non-Commercial License, which permits unrestricted non-commercial use, distribution, and reproduction in any medium, provided the original work is properly cited.

\begin{abstract}
Background: The study was conducted to evaluate safety and tolerability of different components of combined antiretroviral therapy (CART) in pregnant and non-pregnant women and to find out substitute of the drug causing intolerance.

Methods: An observational study on 75 pregnant and 125 non pregnant, HIV infected women receiving CART, over a period of 1 year (Jan 2013-Jan 20140 in SRN Hospital affiliated to MLN Medical college, Allahabad. All women were examined clinically and investigated for baseline hematology, LFT, RFT, S. Cholesterol levels and blood sugar levels. Safety and tolerability of CART was assessed by clinical assessment, investigations done at 6 months interval or earlier if required.

Results: 64\% (48) pregnant women and 60.4\% (63) non pregnant women had Adverse Effects (AE). Most common AE was Liver Function Abnormality (LFA). Among NRTIs, zidovudine was substituted in 42\% (21) pregnant and $17.4 \%$ (11) non pregnant women and among NNRTIs, efavirenz was substituted in $92.3 \%$ (12) pregnant women and $52.6 \%$ (30) non pregnant women.

Conclusions: The safety and tolerability of CART in pregnant and non-pregnant women did not differ by class of $\mathrm{ARV}$, but there were differences among individual drugs. Zidovudine, efavirenz and nevirapine were substituted more commonly in pregnant women.
\end{abstract}

Keywords: Combined antiretroviral therapy, Tolerability, Liver function abnormality, Antiretroviral (ARV) drug

\section{INTRODUCTION}

HIV infection is a disaster that strikes at the very core of a person's life. It is a social stigma and affects a pregnant woman adversely along with her baby even when he or she is in her womb. Being an era of combined antiretroviral therapy (CART) the percentage of people living with Human Immunodeficiency Viral (HIV) infection has leveled off and number of new infection has also fallen as a result of impact of HIV programme. Global prevalence of HIV infection is $0.8 \%$ while in India it is $0.31 \%$. Women living worldwide with
HIV/AIDS are 15.9 million. (2011). Around 2.3 million people in India are living with HIV infection, of these estimate $39 \%$ are females. In India prevalence of HIV infection in females - $0.29 \%$ (2009). Prevalence of HIV infection in pregnant women is $<1 \%$ in India. CART is used in pregnant women to improve her quality of life and to increase her life expectancy along with to prevent Mother To Child Transmission (MTCT). Antiretroviral drugs are medication for the treatment of infection by retroviruses, primarily HIV. When several such drugs typically three or four are taken in combination the approach is known as Highly Active Antiretroviral Therapy of HAART. There are different classes of 
antiretroviral drugs that act on different stages of the HIV life-cycle. Antiretroviral drugs are broadly classified as:

- Nucleoside and Nucleotide Reverse Transcriptase Inhibitors (NRTI) - inhibit reverse transcription and there is synthesis of faulty nucleotide e.g. lamivudine, zidovudivne, didanosine, stavudine.

- Non-Nucleoside Reverse Transcriptase Inhibitors (NNRTI) - inhibit reverse transcriptase directly by binding to the enzyme and interfering with it's function e.g. efavirenz, nevirapine, delavirdine.

- $\quad$ Protease inhibitors - inhibits activity of protease e.g. lopinavir, nelfinavir, ritonavir, saquinavir, indinavir.

Combination antiretroviral therapy (CART) is preferred now a days instead of Monotherapy. According to WHO recommendation Regimens commonly used are:

- 2 NRTIs + 1 NNRTI

- $2 \mathrm{NRTI}+1 \mathrm{PI}$

Commonly used combination:

\section{- Zidovudine + Lamivudine + Nevirapine}

There are some specific side effects associated with specific drugs e.g.: Anaemia \& neutropenia is commonly associated with zidovudine. WHO has divided toxicities into different grades:

Grade 1 (Mild) - Transient or mild discomfort, no limitation in activity. Does not require change in therapy. Symptomatic treatment may be given.

Grade 2 (Moderate) - Limitation in activity. No or minimal medical intervention required. Continue ART if possible if no improvement, consider substitution with drug in same class but in different toxicity profile.

Grade 3 (Severe) - Marked limitation in activity. Medical intervention is required, possible hospitalization. Substitute offending agent without stopping therapy.

Grade 4 (Severe Life threatening) - Extreme limitation in activity, hospitalization required. Discontinue all antiretroviral drugs. Manage medical event until patient stable \& toxicity resolved.

If drug is intolerable then it should be replaced with another drug of same group. e.g. stavudine. In a patient with known liver disease nevirapine should be replaced with efavirenz.

\section{METHODS}

The present study was carried out on pregnant and nonpregnant, HIV infected women on Antiretroviral therapy, attending in-patient and out-patient department of obstetrics and gynaecology in associated hospital of Moti Lal Nehru Medical College Allahabad (i.e. Swaroop Rani Nehru Hospital) in collaboration with Anti-Retroviral Therapy (ART) centre and prevention of parent to child transmission (PPTCT) centre in M.L.N. Medical College Allahabad over a period of twelve months during year 2013-2014.

Written informed valid consent was taken. A detailed history in relation to age, socio-economic status, parity, education, habitat and high risk behavior, was taken. The women were identified from records of booking at PPTCT centre in Obstetrics \& Gynaecology department and ART centre in Medicine department. Patients were seen by obstetrician and gynaecologist in out-patient department of Obstetrics \& Gynaecology department. Non pregnant women were evaluated every month while pregnant women were evaluated monthly till 28 weeks of gestation, fortnightly till 36 weeks and thereafter weekly till 40 weeks or delivery. In both pregnant and nonpregnant woman routine investigations were done and certain specific investigations were carried out to find out adverse effects associated with ART. Liver function test, renal function test, serum total cholesterol levels, serum amylase, blood sugar levels were done to know the safety of antiretroviral drugs. Initial liver tests were done at the start of study and repeated after 8-12 weeks in both the cohorts. Performance of lab test done was consistent in each group. In pregnancy, initial LFTs were done at the first antenatal visit but at least after 16 weeks of gestation. LFT was done by automated analyser and CD4 $\mathrm{T}$ cell count by flow cytometry was done to know the response of anti-retroviral therapy. Analysis of the study data was done with Microsoft Excel XP (Microsoft, Seattle WA) and SPSS version 13.0 (SPSS Inc, Chicago, IL) software on a personal computer. We determined the prevalence, means and standard deviation (SD). Comparison of data between pregnant and non-pregnant women was done using chi square test/student-t test. $\mathrm{P}$ value of $<0.05$ was considered as significant.

\section{RESULTS}

Out of 200 women, 48 (24\%) pregnant women were found to have AEs of ART. 27 (13.5\%) pregnant women were without AEs. Among non-pregnant women, $63(31.5 \%)$ were with AEs because of ART while 62 (31\%) women were without any AE. Prevalence of AEs among pregnant women on ART was $64 \%$ and among non-pregnant women on ART was $60.4 \%$ (Table 1). This difference was not found statistically significant $(\mathrm{P}<0.05)$.

In present study most common adverse effect in both pregnant and non-pregnant women on ART was liver function abnormality [24 (32\%) \& $25(20 \%)$ respectively] next common were anaemia, neutropaenia and rashes in both the groups (Table 2). Among pregnant women on ART with AEs, majority $22(29.3 \%)$ of women were 
having grade $1 \& 2$ liver function abnormality and majority $24(19.2 \%)$ of non-pregnant women on ART were also having grade $1 \& 2$ liver function abnormality. Grade 3 liver function abnormality was detected in 2 $(2.6 \%)$ pregnant women and $1(0.8 \%)$ non pregnant women.

The statistical difference between two groups was found to be insignificant $(\mathrm{P}>0.05$; NS). Grade $1 \& 2$ anaemia was detected in $11(14.6 \%)$ pregnant women while grade 3 anaemia was present only in $2(2.6 \%)$ pregnant women. Grade $1 \& 2$ anaemia was present in 18 (14.4\%) non pregnant women and grade 3 anaemia was present in 2 (1.6\%) non pregnant women. The statistical difference between two groups was not statistically significant (P>0.05; NS).

Table 1: Distribution of pregnant and non-pregnant women according to presence and absence of adverse effects (AEs) of ART.

\begin{tabular}{|lll|}
\hline Patient & Number & Percentage \\
\hline $\begin{array}{l}\text { Pregnant women on ART } \\
\text { with AEs (Group-A) }\end{array}$ & 48 & $24 \%$ \\
\hline $\begin{array}{l}\text { Pregnant women on ART } \\
\text { Without AEs (Group-B) }\end{array}$ & 27 & $13.5 \%$ \\
\hline $\begin{array}{l}\text { Non pregnant women on } \\
\text { ART with AEs (Group-C) }\end{array}$ & 63 & $31.5 \%$ \\
\hline $\begin{array}{l}\text { Non pregnant women on } \\
\text { ART without AEs (Group-D) }\end{array}$ & 62 & $31 \%$ \\
\hline
\end{tabular}

Table 2: Distribution of Group-A and Group-C according to different adverse effects of ART.

\begin{tabular}{|lllll|}
\hline Adverse effects & $\begin{array}{l}\text { Pregnant } \\
\text { women } \\
\text { with A ES }\end{array}$ & $\begin{array}{l}\text { Non pregnant } \\
\text { women with }\end{array}$ \\
& $\begin{array}{l}\text { No. } \\
\text { NoS }\end{array}$ & No. & \% \\
\hline Neutropenia & 8 & 10.6 & 12 & 9.6 \\
\hline Anaemia & 13 & 17.3 & 20 & 16 \\
\hline $\begin{array}{l}\text { Liver function } \\
\text { abnormality }\end{array}$ & 24 & 32 & 25 & 20 \\
\hline Rashes & 1 & 1.3 & 2 & 1.6 \\
\hline Elevated amylase & 1 & 1.3 & 1 & 0.8 \\
\hline Hyperlipidaemia & 0 & 0 & 2 & 1.6 \\
\hline $\begin{array}{l}\text { Impared glucose } \\
\text { tolerance }\end{array}$ & 1 & 1.3 & 1 & 0.8 \\
\hline
\end{tabular}

Table 3A: Comparison of liver function abnormality due to art in pregnant women and non-pregnant women.

\begin{tabular}{|c|c|c|c|c|}
\hline \multirow{2}{*}{$\begin{array}{l}\text { Liver function } \\
\text { abnormality }\end{array}$} & \multicolumn{2}{|c|}{$\begin{array}{l}\text { Pregnant women } \\
(\mathrm{n}=75)\end{array}$} & \multicolumn{2}{|c|}{$\begin{array}{l}\text { Non pregnant } \\
\text { women }(n=125)\end{array}$} \\
\hline & No. & $\%$ & No. & $\%$ \\
\hline Grade $1 \& 2$ & 22 & 29.3 & 24 & 19.2 \\
\hline Grade 3 & 2 & 2.6 & 1 & 0.8 \\
\hline
\end{tabular}

Table 3B: Comparison of liver function abnormality due to art in pregnant women and non-pregnant women.

\begin{tabular}{|lllll|}
\hline Anaemia & $\begin{array}{l}\text { Pregnant women } \\
(\mathbf{n = 7 5})\end{array}$ & \multicolumn{2}{l|}{$\begin{array}{l}\text { Non pregnant } \\
\text { women }(\mathbf{n = 1 2 5})\end{array}$} \\
\cline { 2 - 5 } & No. & \% & No. & \% \\
\hline Grade 1 \& 2 & 11 & 14.6 & 18 & 14.4 \\
\hline Grade 3 & 2 & 2.6 & 2 & 1.6 \\
\hline
\end{tabular}

Table 4: Distribution of women on ART according to substitution of individual anti-retroviral (ARV) drug.

\begin{tabular}{|llll|}
\hline $\begin{array}{l}\text { Antiretroviral } \\
\text { drug }\end{array}$ & $\begin{array}{l}\text { Substitution } \\
\text { events }\end{array}$ & $\begin{array}{l}\text { Total No. } \\
\text { of women } \\
\text { receiving } \\
\text { ARV drug }\end{array}$ & $\begin{array}{l}\% \text { of } \\
\text { substitution }\end{array}$ \\
\hline $\begin{array}{l}\text { Zidovudine (AZT) } \\
\text { (NRTI) }\end{array}$ & 32 & 158 & $20.2 \%$ \\
\hline $\begin{array}{l}\text { Stavudine (d4T) } \\
\text { ( NRTI) }\end{array}$ & 4 & 42 & $9.5 \%$ \\
\hline $\begin{array}{l}\text { Lamivudine (3TC) } \\
\text { (NRTI) }\end{array}$ & 0 & 198 & $0 \%$ \\
\hline $\begin{array}{l}\text { Nevirapine (NVP) } \\
\text { (NNRTI) }\end{array}$ & 22 & 130 & $16.9 \%$ \\
\hline $\begin{array}{l}\text { Efavirenz (EFV) } \\
\text { (NNRTI) }\end{array}$ & 42 & 70 & $35 \%$ \\
\hline
\end{tabular}

Present study showed that in total number of patients, the percentage of substitution was maximum (35\%) for efavirenz with nevirapine followed by zidovudine with stavudine $(20.2 \%)$ and nevirapine with efavirenz $(16.9 \%)$. Among pregnant women with adverse effects, in majority $12 / 13(92.3 \%)$ of women efavirenz was substituted with nevirapine followed by zidovudine with stavudine $21 / 63(33.3 \%)$. In majority $30 / 57(52.6 \%)$ of non-pregnant women also efavirenz was substituted with nevirapine followed by zidovudine with stavudine 11/97 (11.4\%) (Table 5A \& 5B).

Table 5A: Distribution of pregnant and non-pregnant women according to comparison of NRTI substitution.

\begin{tabular}{|lllllll|}
\hline & \multicolumn{2}{l}{ Pregnant women $(\mathrm{n}=75)$} & \multicolumn{3}{c|}{ Non pregnant women $(\mathbf{n}=125)$} \\
\hline Zidovudine & Substitution events & Women on NRTI & $\%$ & Substitution events & Women on NRTI & \% \\
\hline Stavudine & 21 & 63 & 33.3 & 11 & 97 & 11.4 \\
\hline
\end{tabular}


Table 5B: Distribution of pregnant and non-pregnant women according to comparison of NNRTI substitution.

\begin{tabular}{|lllllll|}
\hline NNRTI & $\begin{array}{l}\text { Pregnant women }(\mathrm{n}=75) \\
\text { Substitution } \\
\text { events }\end{array}$ & $\begin{array}{l}\text { Women on } \\
\text { NNRTI }\end{array}$ & $\mathbf{\%}$ & $\begin{array}{l}\text { Non pregnant women }(\mathrm{n}=\mathbf{1 2 5}) \\
\text { events }\end{array}$ & $\begin{array}{l}\text { Women on } \\
\text { NNRTI }\end{array}$ & $\%$ \\
\hline Nevirapine & 15 & 62 & 24.1 & 7 & 68 & 10.2 \\
\hline Efavirenz & 12 & 13 & 92.3 & 30 & 57 & 52.6 \\
\hline
\end{tabular}

\section{DISCUSSION}

This study was conducted to estimate the prevalence of various Adverse Effects (AEs) due to different ARV drugs in pregnant and non-pregnant women and also to estimate substitution of culprit ARV drug. This guided to administer a safe and well tolerable ARV drug in pregnant as well as in non-pregnant women. In present study most common Adverse Effect (AE) of ART was liver function abnormality in both pregnant $(32 \%)$ and non-pregnant (20\%) women, next most common AE was anaemia in both pregnant $(17.3 \%)$ and non-pregnant (16\%) women followed by neutropaenia in pregnant $(10.6 \%)$ and non-pregnant $(9.6 \%)$ women. Other AEs in both the Groups (A \& C) were rashes $(1.3 \% \& 1.6 \%)$, impaired glucose tolerance $(1.3 \%$ \& $0.8 \%)$, hyperlipidaemia $(0 \%, 1.6 \%)$ and elevated amylase levels $(1.3 \%, 0.8 \%)$ respectively. Out of two most common AEs in pregnant and non-pregnant women on ART grade $1 \&$ 2 liver function abnormality was present in $29.3 \%$ pregnant and $19.2 \%$ non-pregnant women while grade $1 \& 2$ anaemia was present in $14.6 \%$ pregnant and $14.4 \%$ non-pregnant women. Grade 3 liver function abnormality was present in $2.6 \%$ pregnant and $0.8 \%$ non-pregnant women. Grade 3 anaemia was present in $2.6 \%$ pregnant and $1.6 \%$ non-pregnant women .In pregnant women both the liver functions and haematological parameters tends to alter because of normal physiological changes during pregnancy, therefor the liver function abnormality and anaemia were more common in pregnant women on ART. Most of the women were unaware of follow up because of illiteracy and rural background so they were getting more adverse effects. The NRTIs are generally well tolerated and cross the placenta. The FDA has classified these as pregnancy class $\mathrm{B}$ or $\mathrm{C}$, depending on the agent. These drugs do bind to mitochondrial DNA gamma polymerase and may cause mitochondrial dysfunction manifesting as cardiomyopathy, neuropathy, lactic acidosis, and liver dysfunction. Genetic susceptibility to these drugs may play a role, and the effects usually resolve with cessation of the medication.

The stavudine has been associated with lactic acidosis and hepatic failure leading to fatalities and should be used with caution or only in cases where other NRTIs cannot be used due to resistance or toxicity. ZDV and stavudine have overlapping toxicities and are antagonistic and should be avoided in combination. Although less information is available regarding NNRTI use in pregnancy, nevirapine and efavirenz both cross the placenta. The most common side effect is rash with nevirapine .Severe nevirapine-associated skin rash and hepatic toxicity had been reported in pregnancy. The potentially fatal hepatotoxicity appears to be increased in women, during pregnancy, and in patients with a $\mathrm{CD}^{+} \mathrm{T}$ cell count greater than 250 cells $/ \mathrm{mL}$. Efavirenz also causes hepatotoxicity and congenital anomalies when using in first trimester so it should not be used as firstline therapy unless no other option is available.

Cooper ER et al. (2002) reported that Women initiating nevirapine with a CD4 greater than 250 cells $/ \mathrm{mm}^{3}$ have a 10 -fold increased risk of developing symptomatic, often rash-associated hepatotoxicity and hepatic failure, zidovudine is associated with bone marrow suppression and pregnant women are more likely to be anemic. Kontorinis N et al. (2003) proposed that the NonNucleoside Reverse Transcriptase Inhibitors (NNRTI) were associated with specific toxicities like liver function abnormalities and cutaneous toxicities significantly. ${ }^{1} 20 \%$ patients on NNRTI were having liver function abnormalities and $11 \%$ were with cutaneous toxicity. Ekouevi AP et al. (2004) found that Grade 3 anaemia $(1.2 \%)$ was rare in pregnant women receiving zidovudine and most frequent adverse effects of long term nevirapine was hepatotoxicity and rashes. ${ }^{2}$ Ouyang DE et al. (2005) did not observe an increased risk of hepatotoxicity among HIV-infected pregnant women on NVP versus other ART, including women who were ART naive. ${ }^{3}$ Dore $G$ et al (2006) found that the major risk factors for severe hepatotoxicity were underlying chronic viral hepatitis (4.5\%), abnormal baseline levels of serum hepatic transaminases $(7.5 \%)$, and nevirapine or high-dose ritonavir-containing antiretroviral therapy regimens $(5.2 \%){ }^{4}$ De Andrade CM (2007) found that pregnant women under antiretroviral therapy present bleeding episodes at delivery, although this therapy promotes a decrease in fibrinolysis in nonpregnant patients, suggesting a prothrombotic state in the former. Since these drugs provoke hepatic disorders, they can cause bleeding disturbances. Ouyang DW et al. (2009) found no significant association between NVP and LEE was observed, regardless of pregnancy status, but pregnancy was significantly associated with increased hepatotoxocity in HIV-infected women. ${ }^{5}$ According to Chaisson RE et al. (2009), severe hepatotoxicity was observed in $15.6 \%$ of patients prescribed NVP and $8.0 \%$ of those prescribed EFV, but only $32 \%$ of NVP and $50 \%$ of EFV-associated episodes were detected during the first 12-weeks of therapy. ${ }^{6}$ Douglas Krakower et al. and 
Rajesh T. Gandhi (2011) reported several toxicities associated with ART in resource limited setting. Most common were anaemia, hepatotoxicity, rashes peripheral neuropathy, nephrotoxicity, lipodystrophy, pancreatitis, gastrointestinal complication, dyslipidemia and cardiovascular events. Present study showed that in 32 (20\%) zidovudine is substituted with stavudine out of 160 women on ZVD. Stavudine was substituted with zidovudine in 4 (10\%) out of 40 women. Maximum 42 (35\%) substitution in 70 women was for efavirenz with nevirapine while in $22(16.9 \%)$ out of 130 women nevirapine was substituted with efavirenz. No substitution was found for lamivudine. In pregnant women zidovudine, stavudine, nevirapine and efavirenz were substituted in $33.3 \%, 20 \%, 24.1 \%$ and $92.3 \%$ women respectively while in non-pregnant women these drugs were substituted in $11.4 \%, 4 \%, 10.2 \%$ and $52.6 \%$ women respectively. Substitution of drugs was higher in pregnant women because they were more prone for adverse effects. Efavirenz was most common drug to be substituted followed by zidovudine. Zidovudine was responsible for most of the cases of anaemia. Hitti et al. (2004) did a clinical trial of nevirapine with zidovudine and lamivudine. All nevirapine related treatment limiting toxicities $(5 / 17,29 \%$ of NVP recipient) occurred in women with CD4 counts $>250$ cells $/ \mathrm{mm}^{3}$ with one case of fatal fulminant hepatic failure. In all these cases NVP was substituted. ${ }^{7}$ Gold et al. (2007) showed an increase in maternal severe adverse effects in zidovudine, lamivudine and nevirapine regimen $(\mathrm{RR}=25.33)$ zidovudine was substituted in $3 / 27,11.1 \%$ patients, lamivudine in $1 / 80,1.25 \%$ patients and nevirapine in $6 / 32,18.75 \%$ patients.

\section{CONCLUSION}

The present study showed that adverse effects because of ART were more common in both pregnant and nonpregnant women who were rural dwellers, illiterate and belonged to lower socio economic status. Adverse effects were more common in pregnant women in comparison to non-pregnant women. Efavirenz was responsible for adverse effects in majority of pregnant and non-pregnant women. Efavirenz, zidovudine and nevirapine were substituted more commonly in pregnant women. Thus regular follow up, early diagnosis of adverse effects and timely substitution of culprit ARV drug may decrease prevalence of adverse effects

Funding: No funding sources

Conflict of interest: None declared

Ethical approval: Not required

\section{REFERENCES}

1. Kontorinis N, Dieterich DT. Toxicity of nonnucleoside analogue reverse transcriptase inhibitors. Semin Liver Dis AIDS. 2003;23:173-81.

2. Ekouevi K, Coffie PA, Becquet R. Antiretroviral therapy in pregnant women with advanced HIV disease and pregnancy outcomes in Abidjan, Cote d'Ivoire. AIDS. 2008;22:1815-20.

3. Ouyang DW, Shapiro DE, Lu M. Increased risk of hepatotoxicity in HIV-infected pregnant women receiving antiretroviral therapy independent of nevirapine exposure. AIDS. 2009;23:2425-30.

4. Dore G. Antiretroviral therapy-related hepatotoxicity: predictors and clinical management. J HIV Ther. 2003;8:96-100.

5. Ouyang DW, Brogly SB, Lu M. Lack of increased hepatotoxicity in HIV-infected pregnant women receiving nevirapine compared with other antiretrovirals. AIDS. 2010;24:109-14.

6. Sulkowski MS, Thomas DL, Chaisson RE, Moore RD. Elevated liver enzymes following initiation of antiretroviral therapy. JAMA. 2000;283:2526-7.

7. Hitti J, Frenkel LM, Stek AM. Maternal toxicity with continuous nevirapine in pregnancy results from PACTG 1022. J Acquir Immune Deficien Syndrom. 2004;36:772-6.

DOI: $10.18203 / 2320-1770 . i j r \operatorname{cog} 20150082$

Cite this article as: Tyagi K, Gupta V. Evaluation of safety and tolerability of antiretroviral therapy in pregnant and non-pregnant women. Int J Reprod Contracept Obstet Gynecol 2015;4:730-4. 